\title{
Doenças de asininos e muares no semiárido brasileiro ${ }^{1}$
}

\author{
André Flávio Almeida Pessoa ${ }^{2 *}$, Clarice Ricardo de Macêdo Pessoa ${ }^{2}$, Eldinê Gomes \\ de Miranda Neto $^{2}$ e Franklin Riet-Correa ${ }^{2}$
}

\begin{abstract}
Pessoa A.F.A., Pessoa C.R.M., Miranda Neto E.G. \& Riet-Correa F. 2014. [Diseases of donkeys and mules in the brazilian semiarid.] Doenças de asininos e muares no semiárido brasileiro. Pesquisa Veterinária Brasileira 34(12):1210-1214. Hospital Veterinário, Centro de Saúde e Tecnologia Rural, Universidade Federal de Campina Grande, Patos, PB 58708-110, Brazil. E-mail: andref_vet@hotmail.com

The diseases of donkeys and mules in the semiarid region of northeastern Brazil were evaluated in a retrospective study of 200 donkeys and 58 mules, in the Veterinary Hospital of Federal University of Campina Grande, from January 2002 to December 2012. Data records of these animals as identification, anamnesis, clinical examination, treatment protocol, and outcome of cases were collected. The affected systems in order of frequency of cases were: integument, 88 cases; musculoskeletal, 78; digestive, 36; nervous, 23; reproductive, 15; and respiratory, 6 . Eight animals were examined before orquiectomy; three animals had inconclusive diagnosis and one animal suffered a bee attack. The main diseases diagnosed in donkeys were traumatic wounds $(32 / 200)$, fractures $(27 / 200)$ and colic $(14 / 200)$. In mules the main diagnoses were colic $(8 / 58)$ and traumatic wounds $(6 / 58)$. Fractures were the main motivation for performing euthanasia $(22 / 200$ donkeys and $3 / 58$ mules). It is concluded that most diagnosed diseases are associated with mistreatment or lack of attention to the animals and should be prevented through awareness and education campaigns of owners and handlers.
\end{abstract}

INDEX TERMS: Equidae, donkeys, mules, diseases, semiarid.

RESUMO.- As doenças de asininos e muares na região semiárida do nordeste do Brasil foram avaliadas em um estudo retrospectivo dos 258 atendimentos realizados no Hospital Veterinário da Universidade Federal de Campina Grande no período de janeiro de 2002 a dezembro de 2012. Dos prontuários desses animais foram coletados dados referentes a identificação, anamnese, exame clínico, diagnóstico, protocolo de tratamento e evolução dos casos. Durante o período analisado foram atendidos 200 asininos e $58 \mathrm{mu}$ ares. Os sistemas afetados foram os seguintes em ordem de frequência: tegumentar, 88 casos; musculoesquelético, 78; digestivo, 36; nervoso, 23; reprodutor, 15; e respiratório, 6. Oito animais foram atendidos para avaliação pré-cirúrgica e encaminhados para orquiectomia; três animais tiveram diagnóstico inconclusivo e um animal sofreu acidente por picada de abelha. As principais enfermidades diagnostica-

\footnotetext{
${ }^{1}$ Recebido em 30 de setembro de 2014.

Aceito para publicação em 8 de dezembro de 2014.

${ }^{2}$ Hospital Veterinário, Centro de Saúde e Tecnologia Rural (CSTR), Campus de Patos da Universidade Federal de Campina Grande (UFCG), Patos, PB 58700-000, Brasil.*Autor para correspondência: andref_vet@hotmail.com
}

das nos asininos foram feridas traumáticas (33/200), fraturas (27/200) e cólica (14/200). Para os muares os principais diagnósticos foram cólica $(8 / 58)$ e feridas traumáticas (6/58). Em ambas as espécies as fraturas foram a principal causa para realização de eutanásia (22/200 asininos e $3 / 58$ muares). Conclui-se que a maioria das doenças diagnosticadas estão associadas com maus tratos ou falta de atenção com os animais e devem ser prevenidas mediante campanhas de conscientização e educação dos proprietários e tratadores, esclarecendo sobre a importância das melhorias do manejo e do bem-estar dos animais.

TERMOS DE INDEXAÇÃO: Equídeos, jumentos, burros, enfermidades, semiárido.

\section{INTRODUÇÃO}

Segundo a Food and Agriculture Organization a população mundial de asininos é de 43 milhões enquanto que a de muares é de apenas 11 milhões. No Brasil há 1,2 milhões de muares e cerca de um milhão de asininos (FAO 2011). $\mathrm{Na}$ região nordeste encontram-se, respectivamente, $90 \%$ e $48,3 \%$ do rebanho de asininos e muares do país (IBGE 
2012). Estes animais exercem importante função de montaria e tração em muitas regiões do mundo. Em países pouco tecnificados, especialmente nas regiões tropicais onde se pratica agricultura de subsistência, o papel destes equídeos é ainda mais importante, sendo, em algumas culturas, utilizados até na alimentação humana (Starkey \& Starkey 2000, Kugleret et al. 2008). Dados da FAO (2011) indicam que acima de 95\% dos rebanhos mundiais de asininos e muares se encontram em países em desenvolvimento.

Apesar do tamanho das populações e de sua importância, pouco se conhece sobre as enfermidades que acometem essas espécies. São raras as publicações científicas acerca do tema em periódicos relevantes na literatura nacional e internacional e no semiárido brasileiro, entre os criadores, há uma tendência de considerar um conceito tradicional de que asininos e muares são animais muito resistentes e que não requerem cuidados em seu manejo. 0 objetivo deste estudo foi conhecer as enfermidades que acometem essas espécies na região semiárida do Brasil mediante estudo retrospectivo dos atendimentos de asininos e muares ocorridos no Hospital Veterinário (HV) da Universidade Federal de Campina Grande (UFCG).

\section{MATERIAL E MÉTODOS}

Foram revisadas as fichas clínicas de asininos e muares atendidos no HV/UFCG no período de janeiro de 2002 a dezembro de 2012. Das fichas foram coletados dados referentes à identificação e anamnese do animal, exame clínico, diagnóstico, protocolo de tratamento e evolução dos casos. Os diagnósticos computados foram realizados por avaliação dos sinais clínicos associados aos achados de exames complementares e em alguns casos foram realizados diagnósticos terapêuticos. As enfermidades foram classificadas pelo sistema afetado. Os casos que afetavam mais de um sistema, os inconclusivos e as avaliações clínicas pré-cirúrgicas foram contabilizados separadamente. Quando necessário, informações adicionais sobre os casos foram pesquisadas nos arquivos dos laboratórios de patologia animal, patologia clínica, diagnóstico por imagem e virologia da própria instituição.

\section{RESULTADOS}

No período analisado foram atendidos 200 asininos (130 machos e 70 fêmeas) e 58 muares (43 machos e 15 fêmeas). As idades informadas para os asininos foram: 8 animais menores de 1 ano; 61 animais de 1-5 anos; e 54 animais com idade igual ou maior que 6 anos. Em 14 atendimentos de asininos a idade não foi informada. Para os muares os valores foram: 1 animal menor de 1 ano, 19 animais de 1-5 anos, 18 animais de 6-10 anos e 14 animais maiores de 11 anos. Em 6 casos a idade do animal não constava na ficha. A maioria dos animais $(228 / 258)$ era proveniente do município de Patos ( $90 \%$ dos asininos e $80 \%$ dos muares) e o restante de municípios circunvizinhos abrangendo uma distância de no máximo $80 \mathrm{~km}$.

Os sistemas afetados foram os seguintes em ordem de frequência: tegumentar, 34\% (68/200) em asininos e 34\% (20/58) em muares; musculoesquelético, 30\% (61/200) em asininos e $29 \%(17 / 58)$ em muares; digestivo, $13,5 \%$ $(27 / 200)$ em asininos e 15,5\%(9/58) em muares; nervoso, $10 \%(6 / 58)$ para muares e $8,5 \%(17 / 200)$ para asininos; reprodutor, 7,5\% (15/200) dos asininos; e respiratório, $2,5 \%(5 / 200)$ e $1,7 \%(1 / 58)$ dos atendimentos de asininos e muares, respectivamente. Além disso, asininos tiveram 1,5\% (3/200) de diagnósticos inconclusivos e 0,5\% $(1 / 200)$ de acidente por picada de abelha. Foi realizada avaliação pré-cirurgica para encaminhamento ao setor de Cirurgia de Grandes Animais, onde foi realizada cirurgia eletiva de orquiectomia, em $8,5 \%$ (5/58) dos muares e em $1,5 \%(3 / 200)$ dos asininos.

Foi observado nesse estudo que as feridas traumáticas na pele foram a principal causa de atendimentos (38/258), afetando 32 asininos e seis muares. Entre as dermatopatias, a neoplasia que totalizou o maior número de casos foi o sarcoide, acometendo 13 asininos e dois muares. As demais neoplasias foram diagnosticadas apenas em muares (três carcinomas de células escamosas, um hemangiopericitoma e um de fibrossarcoma). A única neoplasia que levou a eutanásia (um muar) foi o carcinoma de células escamosas. Dermatopatias de etiologia infecciosa ou parasitária foram diagnosticadas apenasem asininos: abcessos ( 9 casos); dermatofitose ( 4 casos); miíase ( 2 casos); dermatofilose ( 1 caso); e ectoparasitismo por piolho (1 caso). Outras dermatopatias que afetaram apenas asininos foram fotossensibilização primária, dermatite alérgica e tecido de granulação exuberante (1 caso cada). Habronemose ( 3 casos), pitiose (1 caso) e dermatose solar (1 caso) afetaram apenas muares. Sinus provocado por corpo estranho foi a causa do atendimento em 3 asininos e 2 muares. Dados pormenorizados das doenças de pele desses equídeos e também de equinos nessa mesma população são encontrados em Pessoa et al. (2014).

Fraturas foram a segunda enfermidade mais frequente neste estudo $(31 / 258)$ e a primeira para o sistema musculoesquelético, afetando 27 asininos e 4 muares. Os locais afetados foram membros torácicos (14/31), pélvicos (7/31), e múltiplos ossos (politraumatismo) (10/31). Nenhum tratamento foi instituído e a eutanásia foi indicada em todos os casos; no entanto só foi autorizada pelo proprietário em 25 animais (22 asininos e 3 muares). Pododermatite séptica, relativa à infecção ascendente sob a parede do casco (vulgarmente conhecida como broca), foi a segunda maior causa de enfermidades acometendo o sistema musculoesquelético (11/77) afetando 7 asininos e 4 muares. 0 tratamento empregado foi a limpeza local com antisséptico (iodo a $5 \%$ ou pedilúvio com solução sulfato de cobre a 1\%), soro antitetânico e em casos graves, antibioticoterapia a base de penicilina. As outras enfermidades do sistema musculoesquelético encontram-se descritas no Quadro 1.

Tétano foi a principal enfermidade do sistema nervoso diagnosticada neste estudo e a terceira maior causa de atendimentos de asininos (13 animais); para muares, tétano, fratura e pododermatite séptica tiveram o mesmo número de casos (4 cada) as três figurando como terceira posição nas enfermidades mais frequentes para esta espécie. No tétano a letalidade para muares foi de 100\% (4/4) e para asininos $46,16 \%$ (6/13), desses apenas um muar foi eutanasiado; os demais tiveram morte espontânea. 0 número de dias entre o aparecimento dos sinais e o aten- 
Quadro 1. Enfermidades do sistema musculoesquelético de asininos e muares diagnosticadas no Hospital Veterinário da Universidade Federal de Campina Grande, de janeiro de 2002 a dezembro de 2012

\begin{tabular}{lccc}
\hline \multirow{2}{*}{ Diagnóstico } & \multicolumn{3}{c}{ Espécie } \\
\cline { 2 - 4 } & $\mathrm{N}$ & Asininos N(\%) & Muares N(\%) \\
\hline Fratura & 31 & $27(13,5)$ & $4(6,9)$ \\
Pododermatite séptica & 11 & $8(4)$ & $4(6,9)$ \\
Artrite & 8 & $8(4)$ & - \\
Miosite traumática & 4 & $3(1,5)$ & $1(1,73)$ \\
Tenossinovite & 4 & $4(2)$ & - \\
Osteoartrite & 4 & $1(0,5)$ & $3(5,18)$ \\
Calcificação de cartilagem & 2 & - & $2(3,45)$ \\
de falange distal & & & \\
Hérnia umbilical & 2 & $1(0,5)$ & $1(1,73)$ \\
Eventração & 2 & $2(1)$ & - \\
Contratura de tendão flexor & 2 & $2(1)$ & - \\
Luxação & 2 & $1(0,5)$ & $1(1,73)$ \\
Fixação dorsal de patela & 2 & $2(1)$ & - \\
Laminite & 1 & - & $1(1,73)$ \\
Podridão de ranilha & 1 & $1(0,5)$ & - \\
Rabdomiólise de esforço & 1 & $1(0,5)$ & - \\
Periostite & 1 & $1(0,5)$ & - \\
TOTAL & 78 & 61 & 17 \\
& & &
\end{tabular}

dimento clínico variou de 1 a 15 e verificou-se que os casos de morte não foram influenciados pelo número de dias para iniciar o tratamento. Todos os animais foram diagnosticados pelos achados clínicos clássicos (posição de cavalete, cauda em bandeira e prolapso de terceira pálpebra), 10 animais tinham histórico de lesão perfurante anterior ao atendimento; no entanto no momento da consulta a porta de entrada só foi reconhecida em 4 casos (uma na região da nuca e três na sola do casco). Os animais foram tratados utilizando procedimento convencional: soro antitetânico; penicilina; tranquilização com acepromazina; e limpeza do local da ferida (quando localizada) com água oxigenada.

Além de tétano as outras enfermidades do sistema nervoso diagnosticadas foram quatro casos de traumatismo de vértebras com lesão medular (três asininos e um muar) e dois casos de raiva (um em cada espécie). Nos casos de fratura de vértebras os animais apresentaram paralisia de evolução aguda após acidente automotivo ou de manejo. Em todos estes casos foi realizada eutanásia e os achados de necropsia confirmaram o diagnóstico. Nos casos suspeitos de raiva pela avaliação clínica, os animais tiveram morte natural e a confirmação do diagnóstico foi realizada mediante avaliação histopatológica, imunohistoquímica, imunoflourescência direta e inoculação intracerebral em camundongos de amostras de encéfalo e medula.

Cólica (ou abdômen agudo) foi a quarta maior causa de atendimentos (22/258). Para muares foi o principal diagnóstico em 13,8\% dos casos (8/58), com uma letalidade de 50\%; para asininos representou $7 \%$ dos atendimentos $(14 / 200)$, com $4(28,6 \%)$ óbitos por essa causa. As principais causas de cólica para asininos foram a compactação do intestino grosso, o parasitismo intestinal (família Strongyloidea) e a ingestão de alimentos fermentados. Para os muares as principais causas foram a compactação e a formação de fitobenzoários no intestino grosso. A síndrome cólica nestas espécies ocorreram associadas a falhas no manejo (sanitário e alimentar) e a sazonalidade, sendo observadas principalmente na estação seca, outros detalhes sobre a epidemiologia da cólica em equídeos no semiárido foram publicados anteriormente por Pessoa et al. (2012).

Pontas dentárias foi uma afecção do trato digestivo que afetou 4 asininos e 1 muar. Os animais foram tratados com grosagem, com alta médica imediata. Asininos apresentaram também verminose intestinal (5 casos), abscessos dentários (2 casos) e laceração da língua (2 casos). Nos casos de verminose os animais apresentavam baixo escore corporal e mucosas pálidas; exames parasitológicos foram realizados e observada a presença de ovos da família Strogyloideae. Foi receitado anti-helmíntico e indicada melhora nos manejos sanitário e nutricional. Os abscessos dentários localizavam-se na arcada dentária inferior, em ambos os casos, e drenavam exsudato purulento para o exterior da cavidade oral através do ramo damandíbula, foram tratados através de curetagem. Nos dois casos de laceração de língua que foram diagnosticados a causa da lesão não foi esclarecida; e ambos foram encaminhados ao setor de cirurgia para reconstrução do órgão.

Entre as doenças do sistema reprodutor a principal foi o parto distócico, afetando seis jumentas. Pelos dados registrados nas fichas de atendimento foi possível identificar a distocia por mau posicionamento fetal em dois casos; nos demais não foi possível determinar a origem do problema. Em todos os casos os fetos estavam mortos e em um caso a fêmea morreu em decorrência de complicações no pós-parto (laminite). Os casos de ferida lacerante em órgão genital (testículos, pênis e vulva) ocorreram em três machos e uma fêmea. A causa dos ferimentos nos machos foi atribuída a arame farpado, faca ou metal pontiagudo, infligidos por terceiros e na fêmea foi causado por autotraumatismo em cerca. Os machos foram encaminhados para o setor de Cirurgia de Grandes Animais para síntese do ferimento, em um caso mais grave foi efetuada a amputação de pênis e orquiectomia. Na fêmea como havia presença de tecido necrosado e mí́ase foi realizado debridamento e síntese da ferida cirúrgica. Metrite foi observada em três jumentas, uma após aborto e duas após o parto. De acordo com os proprietários, nos três casos, inicialmente foi observado corrimento serossanguinolento evoluindo para purulento. Estes animais foram tratados com antibiótico sistêmico e lavagem uterina com soro fisiológico e antibiótico, as três tiveram alta. Um asinino foi atendido devido a funiculite decorrente de infecção após cirurgia de castração realizada 45 dias antes. Para esse animal foi indicado a remoção do tecido afetado, sendo encaminhado para o setor de Cirurgia de Grandes Animais. No único caso de orquite o animal apresentava contusão caracterizada por edema acentuado e aumento de temperatura e de sensibilidade dos testículos e escroto. Após exame clínico a suspeita foi de orquite traumática por instrumento contundente; neste caso optou-se pela orquiectomia.

Das doenças do sistema respiratório, apenas três foram diagnosticadas no período estudado; três asininos adultos apresentaram broncopneumonia caracterizada por presença de estertores na auscultação; a evolução desde a observação dos sinais até o atendimento clínico foi de 5, 
30 e 60 dias. Em nenhum caso o agente etiológico foi pesquisado. Em dois asininos que apresentavam secreção purulenta na cavidade nasal foi diagnosticado garrotilho. Um muar foi diagnosticado com empiema das bolsas guturais decorrente de complicações secundárias ao garrotilho. 0 animal apresentava aumento de volume na região do ramo da mandíbula e refluxo alimentar pelas narinas. Todos os problemas respiratórios foram tratados com antibioticoterapia sistêmica, no caso de broncopneumonia utilizou-se, também, expectorante, e todos os animais se recuperaram.

\section{DISCUSSÃO}

Os resultados deste levantamento demonstram que os sistemas tegumentar, locomotor e digestivo foram os mais afetados. As feridas traumáticas na pele, fraturas e cólica foram as enfermidades mais frequentes para asininos. Para muares as principais enfermidades foram cólica e feridas traumáticas.

Os raros estudos sobre doenças de asininos, apontam que os parasitas internos, problemas nos cascos e feridas são os problemas mais comuns para esta espécie nos países em desenvolvimento (El Dirdiri et al. 1986, Aluja \& Lopez 1991, Rodriguez-Maldonado et al. 1991, Yilma et al. 1991, Saul et al. 1997, Ayele et al. 2006). Esses resultados se assemelham aos obtidos neste levantamento apenas no referente às feridas traumáticas, pois outras enfermidades tiveram maior frequência neste levantamento do que verminose e problemas de cascos. Na Inglaterra um levantamento identificou as desordens dentárias, doenças vasculares, artrite e afecções podais como os quatro principais achados de necropsia em asininos (Morrow et al. 2011).

Ficou evidenciada no presente trabalho a importância das lesões de natureza traumática em asininos. As causas para as lesões traumáticas observadas em animais no semiárido nordestino e em outras regiões do mundo (Aluja \& Lopez 1991, Mohammed 1991), possivelmente estejam relacionadas com métodos de contenção e de equipamentos de trabalho inadequados e com maus tratos, o que está associado, provavelmente, a cultura, pobreza e/ou falta de educação e outros problemas sociais das pessoas envolvidas no manejo e trabalho com os equídeos. Tais situações sociais impõem pressões econômicas graves nas pessoas que são susceptíveis a reduzir a percepção da importância do bem-estar dos animais infligindo a eles castigos físicos e manejo inadequado (Aluja \& Lopez 1991).

A principal causa para eutanásia verificada nesse estudo foram as fraturas. 0 grande número de equídeos eutanasiados por essa causa já havia sido observada em outro estudo sendo associada à dificuldade de correção cirúrgica em animais de grande porte (Pierezan et al. 2009). Nesse estudo verifica-se também que o valor do animal é inferior aos gastos com os procedimentos, além dos animais necessitarem de um longo período para recuperação, dessa forma os proprietários dão preferência à substituição do animal. Também verifica-se que muitos desses animais, especialmente asininos, são criados soltos com livre acesso a rodovias e em alguns casos esses animais são causadores de acidentes de trânsito. Na Índia a maioria das mortes de asininos é devido aos acidentes de trânsito (Ramachandran
\& Srinivas 1991). Em levantamento da Polícia Rodoviária Federal contabilizou-se 452 acidentes causados por asininos em rodovias da Paraíba no período janeiro de 2009 a janeiro de 2014, desses 412 ocorreram na região do sertão onde localiza-se o município de Patos (SIGER/PRF 2014).

A frequência das enfermidades do aparelho locomotor em equídeos aumenta quando esses animais são utilizados no esporte ou no trabalho. Os asininos e muares neste estudo eram utilizados em sua maioria na tração de carroças. As principais afecções de aparelho locomotor de equídeos de tração diagnosticadas em um levantamento realizado no Brasil foram as tendinites/tenossinovites e as lesões osteoarticulares (Maranhão et al. 2006). Embora na literatura não haja trabalhos sobre a relação entre a saúde animal e a carga de trabalho, os autores inferiram que as lesões nos tendões e bainha tendíneas podem estar associadas à falha no condicionamento dessas estruturas quando a tração ocorre de forma repentina, por alterações biomecânicas provocadas por desequilíbrios podais e/ou pelo acúmulo contínuo de pequenas injúrias pela sobrecarga de peso. Enquanto que as lesões articulares, especialmente na articulação társica, são achados esperados nos animais de tração, pois as articulações nessa atividade são muito exigidas ao suportar cargas compressivas em baixa velocidade (Adair et al. 1992, Stashak 2006).

A segunda principal causa de atendimento do sistema musculoesquelético foram as afecções de casco, dentre elas a mais relevante foi a pododermatite séptica. Essa enfermidade se dá pela contaminação de fissuras na linha branca produzidas pelo contato com superfície áspera ou a partir de penetração de pequenos corpos estranhos. A permanência em ambiente úmido e sujo facilita a contaminação bacteriana. A lesão produz um trajeto fistuloso que drena acima da faixa coronária ou dos bulbos do talão. É uma condição frequente em equinos e cursa com claudicação aguda procedida de aparecimento do abscesso drenante dentro de um a dois dias podendo progredir para condições mais graves como laminite e osteíte podal (Stashak 2006). Muitos casos de pododermatite séptica poderiam ser evitados através da conscientização de tratadores e proprietários sobre a profilaxia da enfermidade.

Distocias são observadas em 1 a $4 \%$ dos partos de asininos (Pugh 2002). A prevalência de parto distócico encontrada nesse estudo foi de $3 \%$, semelhante à verificada num levantamento de mesma natureza realizado no Sudão $(3,1 \%)$ (Siham et al. 2008). Apenas asininos foram afetados por problemas reprodutivos. Essa realidade era prevista principalmente em condições envolvendo o parto, devido à fisiologia dos muares que são híbridos não férteis. Diferente das éguas, a distocia materna não é condição rara em jumentas, essa característica se deve às diferenças anatômicas da cervix e vagina desses animais (Morrow 1986, Pugh 2002).

Neste estudo verificou-se um caso raro de acidente por abelhas afetando um asinino, que sobreviveu. $\mathrm{O}$ animal foi tratado com corticoide e fluidoterapia. No Brasil esse acidente é causado pelo ataque de enxame de abelhas africanizadas do gênero Apis, as múltiplas picadas desse inseto injetam veneno contendo fosfolipases que causam hemóli- 
se intravascular e edema de glote. A morte nesses casos se dá por insuficiência respiratória e renal aguda (Barravieira 1999).

\section{CONCLUSÕES}

A maioria das doenças diagnosticadas neste estudo está associada com maus tratos ou falta de atenção com os animais, devendo haver uma melhor conscientização dos proprietários e tratadores, quanto a importância do bem-estar animal e a melhoria do seu manejo alimentar e sanitário.

0 livre acesso dos asininos e muares às rodovias deve ser evitado prevenindo assim os acidentes automobilísticos envolvendo estes animais.

\section{REFERÊNCIAS}

Aluja A.S. \& Lopez F. 1991. Donkeys in Mexico, p.1-7. In: Fielding D. \& Pearson R.A. (Eds), Donkeys, Mules and Horses in Tropical Agricultural Development. CTVM, Edinburgh. 329p.

Adair H.S. 1992. Common lameness problems of the draft horse, p.85-91. In: Robison N.E. (Ed.), Current Theraphy in Equine Medicine. W.B. Saunders, Pensilvania.

Ayele G., Feseha G., Bojia E. \& Joe A. 2006. Prevalence of gastro-intestinal parasites of donkeys in Dugda Bora District, Ethiopia. Livestock Research for Rural Development. Disponível em <http://www.lrrd.org/ lrrd18/10/ayel18136.htm, Article \#136> Acesso em 21 ago. 2014.

Barraviera B. 1999. Acidentes por abelhas e vespas, p.339-344. In: Barraviera B. (Ed.), Venenos: aspectos clínicos e terapêuticos dos acidentes por animais peçonhentos. EPUB, Rio de Janeiro. 411p.

El Dirdiri N.I., Damir H.A. \& Wahbi A.A. 1986. Disease incidence in donkeys (Equus asinus asinus) with emphasis on strongyle infection. Acta Veterinaria, Yugoslavia, 36(5/6):313-320.

FAO 2011. Food and Agriculture Organization, United Nations, Rome. Disponível em <http://faostat.fao.org/site/573/DesktopDefault> Acesso em 24 ago. 2014.

IBGE 2012. Produção da Pecuária Municipal (PPM). Instituto Brasileiro de Geografia e Estatística, Rio de Janeiro, RJ. 63p.

Kugler W., Grunenfelder H. \& Broxham E. 2008. Donkey breeds in europe: inventory, description, need for action, conservation. Report 2007/2008. Monitoring Institute for Rare Breeds and Seeds in Europe. Disponível em <www.save-foundation.net/english/monitor.htm> Acesso em 11 set. 2014

Maranhão R.P.A., Palhares M.S., Melo U.P., Rezende H.H.C., Braga C.E. \& Silva Filho J.M. 2006. Afecções mais frequentes no aparelho locomotor dos equídeos de tração no município de Belo Horizonte. Arq. Bras. Med. Vet. Zootec. 58:21-27.

Mohammed A. 1991. Management and breeding aspects of donkeys around Awassa, Ethiopia, p.185-188. In: Fielding D. \& Pearson R.A. (Eds), Donkeys, Mules and Horses in Tropical Agricultural Develop- ment. CTVM, Edinburgh. 329p. <http://www.vetwork.org.uk/donkey. htm\#> Acesso em 21 ago.2014.

Morrow D.A. 1986. Current therapy in Theriogenology. W.B. Saunders, Philadelphia, p.158-159.

Morrow L.D., Smith K.C., Piercy R.J., Du Toit N., Burden F.A., Olmos G., Gregory N.G. \& Verheyen K.L.P. 2011. Retrospective analysis of post-mortem findings in 1,444 Aged Donkeys. J. Comp. Pathol. 144(2/3):145-156.

Ramachandran S. \& Srinivas R.P. 1991. The contribution of the donkey and pony to the economy of rural low-income groups in Karnataka State, South India, p.20-21. In: Fielding D. \& Pearson R.A. (Eds), Donkeys, Mules and Horses in Tropical Agricultural Development. CTVM, Edinburgh. 329p.

Rodriguez-Maldonado G. 1991. The principal problems in working donkeys in Mexico (Abstract), p.138-139. In: Fielding D. \& Pearson R.A. (Eds), Donkeys, Mules and Horses in Tropical Agricultural Development. CTVM, Edinburgh. 329p.

Pessoa A.F.A., Miranda Neto E.G., Pessoa C.R.M., Simões S.V.D., Azevedo S.S. \& Riet-Correa F. 2012. Abdômen agudo em equídeos no semiárido do Nordeste do Brasil. Pesq. Vet. Bras. 32(6):503-509.

Pessoa A.F.A., Pessoa C.R.M., Miranda Neto E.G., Dantas A.F.M. \& Riet-Correa F. 2014. Doenças de pele em equídeos no semiárido brasileiro. Pesq. Vet. Bras. 34(8):743-748.

Pierezan F., Rissi D.R., Rech R.R., Fighera R.A., Brum J.S. \& Barros C.S.L. 2009. Achados de necropsia relacionados com a morte de 335 equinos: 1968-2007. Pesq. Vet. Bras. 29(3):275-280.

Pimentel L.A., Oliveira D.M., Galiza G.J.N., Rego R.O., Dantas A.F.M. \& Riet-Correa F. 2009. Doenças do sistema nervoso central de equídeos no semi-árido. Pesq. Vet. Bras. 29(7):589-597.

Pugh D.G. 2002. Donkey reproduction. Proc. Am. Assoc. Equine Pract. 48:113-114.

Saul C., Siefert L. \& Opuda-Asibo J. 1997. Disease and Health problems of donkeys: a case study from eastern Uganda. In: Improving donkey utilization and management. ATNESA Workshop. Held 5-9 May, Debre-Zeit, Ethiopia, p.58-63.

Siham E.S., Abdalla M.A., Amel O.B. \& Rabab M.A. 2008. Investigation of major disease affecting donkeys (Equus asinus) in Khartoum State-Sudan. $13^{\text {th }}$ Sci. Congr. Fac. Vet. Med. Assiut. Univ. Egypt, p.791-796.

SIGER/PRF 2014. Sistema Informações Gerenciais/Polícia Rodoviária Federal. 14ํㅡㄴ Superintendência de Polícia Rodoviária Federal/PB.

Starkey P. \& Starkey M. 2000. Regional and World trends in Donkey Populations. p.10-21. In: Starkey P. \& Fielding, D. (Eds), Donkeys, People and Development: a resource book of the Animal Traction Network for Eastern and Southern Africa (ATNESA). ACP-EU Technical Centre for Agricultural and Rural Cooperation (CTA), Wageningen, The Netherlands. 247p.

Stashak T.S. 2006. Claudicação em equinos segundo Adams. 5aㅡ ed. Roca, São Paulo. 1112p.

Yilma J.M., Feseha G.A., Svendsen E.D. \& Mohammed A. 1991. Health problems of working donkeys in Debre-Zeit and Menagesha Regions of Ethiopia, p.151-155. In: Fielding D. \& Pearson R.A. (Eds), Donkeys, Mules and Horses in Tropical Agricultural Development. CTVM, Edinburgh. 329p. 